\title{
The dam slope stability under the transient condition during an extreme flood
}

\author{
Svitlana Velychko ${ }^{1, *}$, and Olena Dupliak ${ }^{1}$ \\ ${ }^{1}$ Kyiv National University of Construction and Architecture, Faculty of Engineering System and Ecology, 31 Povitroflotsky Ave., Kyiv, \\ 03037, Ukraine
}

\begin{abstract}
Mountain Flood Control Reservoir (MFC Reservoir) is used to reduce the flood level in the mountainous area and protect settlements downstream. The special feature of this MFC Reservoir is the fast filling during 1-2 days, short storage time at the maximum level and speed falling of the water level. Simulation of the MFC Reservoir operation was carried out on the software Midas GTS NX. Two rockfill dam models were developed: with the core and with the screen. The fluctuation of the water level in the MFC Reservoir was taken as the transformed flood from $1 \%$ to $10 \%$ probability. The fast water level change in the MCF Reservoir creates the transient seepage condition during the flood. During the water level rising in the MFC Reservoir, the upstream slope stability gradually increases because of hydrostatic pressure. After the water level begins to fall with rate of $0.7 \mathrm{~m} /$ hour, the slope stability decreases. The core or screen location significantly affects the stability of the upstream dam slope. The simulation showed that the upstream slope of the dam with the core was more stable. Due to the high hydraulic conductivity, the upstream dam prism with the berm significantly dampens the pore pressure in the dam and increases the stability of the upstream slope.
\end{abstract}

\section{Introduction}

The floods take place both in winter and in the warm period, but cold floods have the higher flow rates in the Transcarpathian region. Due to the unstable temperature regime in winter, the frequent thaws are observed in the Tisza river basin, during which extreme cold floods are formed. In the mountainous part of the Tisza river basin floods have the high flow rate and short lag time, due to steep floodplain slopes and riverbed slope, the duration of flood does not exceed 3-5 days.

One of the active flood protection measure to lower water levels is using Mountain Flood Control Reservoir, which transforms the extreme flood flow of $1 \%$ probability to safe one. The safe flood flow which provides the sustainability of the river ecological system is estimated as Channel-forming flow of 5\% - 35\% probability for Tisza River basin according researchers in the work [1].

Mountain Flood Control Reservoir is created by dam with the bottom spillway. The spillway is designed for discharge of Channel-forming flow which passes without changing downstream. In the case of the extreme flood, the part of the river runoff that exceeded the Channelforming flow is temporarily accumulated in the MFC Reservoir formed by the dam [2]. To save vegetation diversity inside the MFC Reservoir area, the duration of the water storage in the MFC Reservoir should not exceed 8-10 days, during which the water gradually flows downstream.
During the period of flooding the water level rises rapidly and the same rapid falls. During the rapid water rising in the MFC Reservoir, the pore pressure increases in the dam prism and the seepage is directed to the downstream slope. As the water level falls in the MFC Reservoir, the direction of seepage changes to the upstream slope with the gradual decrease in pore pressure. The rapid change of the water level in the Reservoir does not enable to stabilize the seepage, as the water penetration into the dam body is partial and transient [3, 4]. The depth of water penetration into the dam body affects the slope stability.

The calculations of authors [5-10] showed that the slope Safety Factor decreasing during the intense water level falling under the steady state seepage condition at the initial time, and if the water level was getting higher the Safety Factor increased in the water reservoir [11]. Decrease in slope stability is noted also under the transient seepage conditions as water penetrates into unsaturated soil during the rain that leads to increase of the phreatic surface $[7,12,13]$. In the article [14] is noted that Safety Factor of the clay slope during the rapid rising and falling (transient condition) decreases less than the Safety Factor calculated during the water falling from steady high level in the water reservoir. Therefore, it should be expected that Safety Factor of the upstream slope will decrease but the dam stability will be higher during the Mountain Flood Control Reservoir operation than when the water level falls suddenly after prolonged standing at a high level as in the typical water reservoir.

\footnotetext{
* Corresponding author: velychko.sv@knuba.edu.ua
} 
The transient analysis requires additional parameters of unsaturated soil, such as volumetric water content function, hydraulic conductivity function, residual water content [15]. Not all unsaturated parameters have a significant impact on the results of calculations, in the works $[4,16]$ were noted that saturated hydraulic conductivity had greater impact on the slope stability, than the volumetric water content function, which could be determined by theoretical methods. In the article [17] Safety Factors for slope at the different hydraulic conductivity and water falling rate were studied and established that the slope stability was not depend on the water falling rate if the saturated hydraulic conductivity of the slope was $0.2 \mathrm{~m} /$ hour and above.

To reduce construction cost, the dam of the Mountain Flood Control Reservoir is made of local materials, the quarries of which are located nearby. The most common building material in the mountainous part of the Carpathians is the gravel-pebble soil, the mechanical properties of which meet the requirements of the dam construction regulations. This material has the high saturated hydraulic conductivity of 30-50 m/day, which requires the use of the impermeable layer.

There are enough clay materials with low hydraulic conductivity of $0.01-0.07 \mathrm{~m} /$ day in Carpathians region, so two types of dam, the dam with the core and with the screen were considered in this article. The dam with screen simplifies the process of construction and operation of the dam, at the same time the dam with the clay core is more stable during seismic activity. Therefore, it is necessary to investigate whether the presence of the clay screen will affect the upstream slope stability and which of the impermeable structures will be more reliable for MFC Reservoir.

Mountain Flood Control Reservoir leads to the temporary intensive water level rising and falling during the extreme flood, which may reduce the upstream dam slope stability. This problem can be solved by simulating transient seepage by means of finite element method. Assessment of the slope stability under transient conditions is an urgent task that will ensure the reliability of flood protection. The stability of the upstream dam slope and transient seepage analysis were carried out by the Stress Analysis Method (SAM) and the Stress Reduction Method (SRM) using the software Midas GTS NX (version 2.1).

The purpose of the work is to simulate the possibility of dangerous landslide processes of the upstream dam slope during the MFC Reservoir operation under the transient seepage condition of unsaturated soil and to determine the optimal design of the impermeable structure of the rockfill dam.

\section{Methods}

\subsection{Mountain Flood Control Reservoir}

Expected location of the Mountain Flood Control Reservoir is the Irshava River of the mountainous part of the Tisza river basin. The main function of the MFC Reservoir to protect settlements of Brid, Zagattya, Irshava against floods and to lower flood water level in the river. The catchment area of the MFC Reservoir is $71.4 \mathrm{~km}^{2}$. The height of the dam is $19.6 \mathrm{~m}$. The upstream slope is $1: 2.5$, and the downstream slope is 1:2.25. Dam structure is shown on the fig. 1 . The berms of $3.0 \mathrm{~m}$ wide are formed on the upstream and downstream slopes to increase the slope stability, and are used as cofferdam during construction period. The upstream slope is covered with the riprap. The base of the dam is strong dark grey Basaltic andesite, which is cracked near the surface with saturated hydraulic conductivity of $0.01-0.1 \mathrm{~m} /$ day.

The modern alluvial deposits of boulder-gravelpebble materials on loamy aggregate which covers mountain base, should be removed out of the dam pit.

\subsection{Extreme floods}

Floods occur several times a year in Transcarpathian region, and extreme floods occur periodically: 1947, 1957, 1968, 1970, 1992, 1998, 2001, 2008, 2010, 2019. The flood of November 1998 is one of the most catastrophic in the recent years. It covered all the rivers of Tisza basin and it was formed by prolonged rains. Intense and prolonged rains led to the water levels rise up to 2.5$6 \mathrm{~m}$ in the rivers on the $4^{\text {th }}$ of November, 2020.

To simulate the Mountain Flood Control Reservoir operation hydrograph of the flood of $1 \%$ probability was taken that was equal to $181 \mathrm{~m}^{3} / \mathrm{s}$ for the Irshava River. The flood water level raising to the maximum flow occurs in 12.4 hours, the level falls slower during 43.3 hours. The transformed flood flow, which flows through the bottom spillway to the downstream, is shown in fig. 2 (red line) and equal to $103 \mathrm{~m}^{3} / \mathrm{s}$. The storage of the flood in the MFC Reservoir enables to reduce the flood flow twice due to stretching of the maximum flow in time. The water storage continues for the short time of 15 hours, then water level falls along 30 hours. The transformed flood hydrograph was converted into the relationship between water level and time by means of the flow rate and total head function.

This relationship between water total head and time was used to simulate MFC Reservoir operation during flood event.

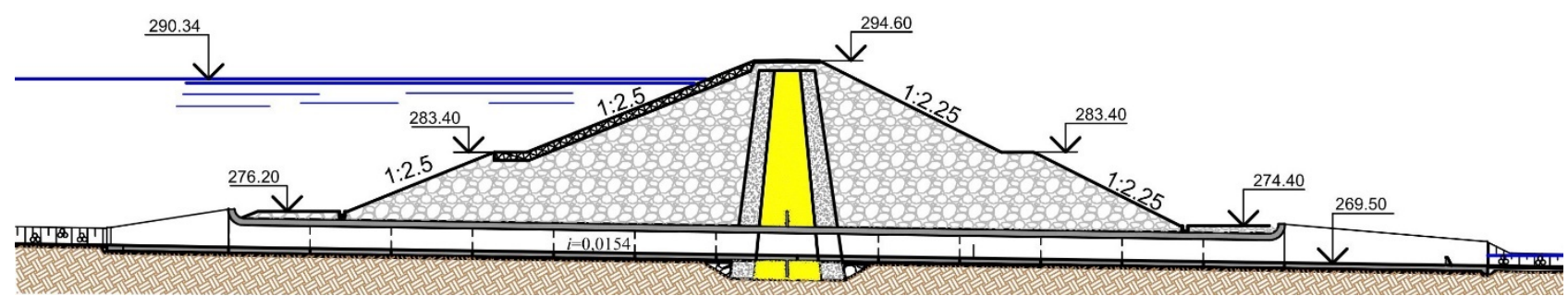

Fig. 1. Mountain Flood Control Reservoir dam with core. 


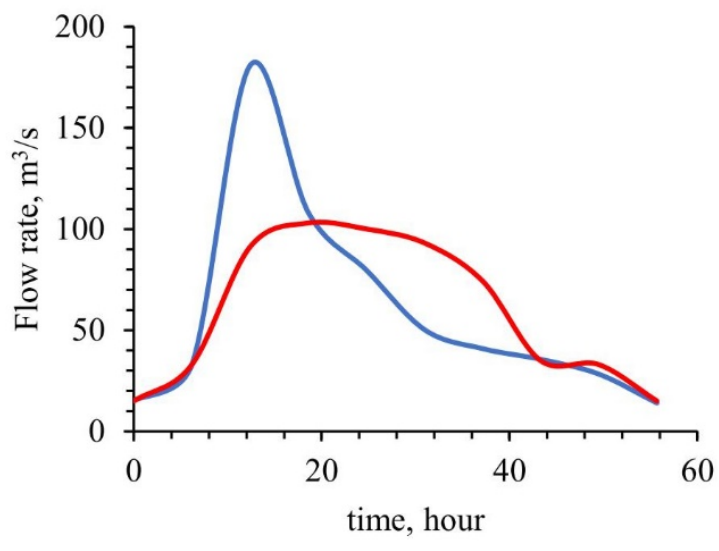

Flood 1\% — Transformed flow

Fig. 2. The flood hydrographs of $1 \%$ and transformed flow downstream.

\subsection{Soil properties of the dam and the base}

The soil of the gravel-pebble with loamy aggregate for the dam prisms is classified as GM, the core and screen of heavy loam is classified as SC according to the Unified Soil Classification System. The base is Basaltic andesite cracked on the top and water saturated.

The mechanical properties of the soils of the dam and the base were obtained as a result of field surveys and laboratory processing of the samples. The soil property which were taken into account during simulation are shown in table 1.

Table 1. The soil properties of the dam and the base.

\begin{tabular}{|c|c|c|c|}
\hline Propertied & $\begin{array}{c}\text { Prism } \\
\text { (GM) }\end{array}$ & $\begin{array}{c}\text { Core, screen } \\
\text { (SC) }\end{array}$ & Bedrock \\
\hline Elastic Modulus, $\mathrm{MPa}$ & 25 & 22 & 150 \\
\hline Unit Weight, $\mathrm{kN} / \mathrm{m}^{3}$ & 21.3 & 19.6 & 21 \\
\hline Cohesion, $\mathrm{kPa}$ & 1 & 16 & 30 \\
\hline Internal friction angle, $^{0}$ & 30 & 23 & 36 \\
\hline $\begin{array}{c}\text { Hydraulic conductivity, } \\
\mathrm{m} / \text { day }^{3}\end{array}$ & 19.9 & 0.067 & 0.001 \\
\hline Porosity, $\mathrm{m}^{3} / \mathrm{m}^{3}$ & 0.46 & 0.58 & 0.3 \\
\hline
\end{tabular}

\subsection{Transient seepage analysis of the Mountain Flood Control Reservoir}

Simulations of the transient seepage in the dam during water level increasing and falling were made using the semi-coupled Seepage-Stress-Slope Analysis by the Midas GTS NX software. The Darcy`s equation is solved by the finite element method:

$$
\frac{\partial}{\partial x}\left(k_{x} \frac{\partial H}{\partial x}\right)+\frac{\partial}{\partial y}\left(k_{y} \frac{\partial H}{\partial y}\right)+Q=\frac{\partial \theta}{\partial t},
$$

where $H$ is total head; $k_{x}, k_{y}$ are the hydraulic conductivity in the horizontal and vertical directions, respectively; $Q$ is boundary discharge; $\theta$ is the volumetric water content; $t$ is the time.

The volumetric water content functions and the hydraulic conductivity functions of unsaturated soils for the prism GM, core (SC) and screen (SC) were set to simulate transient seepage analyses. The base was taken as saturated with the hydraulic conductivity according to table 1. It was assumed that the dam had already built and initial deformation was finished, for which the stage of zero initial deformations was entered during the calculations. The initial water level was set at the level of $1.0 \mathrm{~m}$ above the base of the dam which corresponded to the water level in the river before the flood, the initial stage of steady state seepage analysis was made to simulate water in the river. The influence of the rain and the possible evaporation from the surface of the dam were not simulated.

\subsection{The upstream slope stability analysis}

The Stress Analysis Method (SAM) is the limit equilibrium method, in which the Safety Factor is determined for the several circular sliding surfaces using the results of the stress calculation by the finite element method. The Safety Factor is calculated by equation:

$$
S F=\frac{\dot{\int_{S}} \tau_{f} d \Gamma}{\int_{S} \tau_{m} d \Gamma}
$$

where $\tau_{m}$ is shear stress, which determined as a result of calculation; $\tau_{f}$ is shear stress, which for the MohrCoulomb criterion is calculated by equation:

$$
\begin{gathered}
\tau_{f}=c+\sigma_{n} \operatorname{tg} \varphi, \\
\tau_{m}=0.5\left(\sigma_{y}-\sigma_{x}\right) \sin 2 \theta+\tau_{x y} \cos 2 \theta, \\
\sigma_{n}=\sigma_{x} \sin ^{2} \theta+\sigma_{y} \cos ^{2} \theta-\tau_{x y} \sin 2 \theta,
\end{gathered}
$$

where $c$ is cohesion; $\varphi$ is internal friction angle; $\theta$ is the angle between the sliding surface and horizon; $\sigma_{n}$ is the total normal stress; $\sigma_{x}, \sigma_{y}$ are normal stress in the horizontal and vertical directions, respectively; $\tau_{\mathrm{xy}}-$ shear stress in $\mathrm{x}$ - and $\mathrm{y}$-directions at the base centre.

The Stress Reduction Method (SRM) is based on the gradual decrease in shear stress until the slope reaches limit equilibrium state, the minimum value of the Safety Factor using the Mohr-Coulomb criterion is determined by the equation:

$$
\begin{gathered}
S F=\frac{\mathrm{c}+\sigma_{n} \operatorname{tg} \varphi}{\frac{c}{S R F}+\sigma_{n} \operatorname{tg} \varphi_{f}}, \\
\varphi_{f}=\operatorname{tg}^{-1}\left(\frac{\operatorname{tg} \varphi}{S R F}\right),
\end{gathered}
$$

where SRM - Stress Reduction Factor.

The Stress Reduction Method enables to simulate the sliding surface which is close to the real form of sliding surface without preliminary adopted potential sliding surfaces that is the great advantage over the other methods in which it is necessary to set sliding surfaces $[18,19]$.

The two-dimensional model was used to simulate the Mountain Flood Control Reservoir operation. Since the size of the mesh affects the calculations accuracy before the simulation, the optimal mesh size was accepted by gradually reducing the mesh size from $2.0 \mathrm{~m}$ to $0.5 \mathrm{~m}$. The simulation was carried out for dam with core. The mesh size of $1.0 \times 1.0 \mathrm{~m}$ was set for dam, and the variable mesh 
from $1.0 \mathrm{~m}$ to $2.0 \mathrm{~m}$ for the base as further mesh reduction significantly increases the calculation time and practically does not increase the Safety Factor accuracy, the similar result was obtained in the work [20].

The Mohr-Coulomb model was used for the soil simulation. Two dam construction were simulated: the location of the impermeable layer in the middle of the dam (dam with core) and the impermeable layer location near the upstream prism (dam with screen). The flood hydrograph was divided by regular intervals every 5 hours. The following assumptions were made during the simulation:

- $\quad$ the parts of the model (prism, core, screen, base) were accepted as homogeneous and isotropic; unsaturated condition were assumed to be the same;

- the hydraulic conductivities are isotropic;

- the maximum hydraulic conductivity is equal to the water permeability;

- the seepage inside the dam is transient;

- the initial water level is set at the level of $1.0 \mathrm{~m}$ above the base.

\section{Results and discussion}

The phreatic surface location inside the dam during the rise of water level at first 30 hours of the flood is shown in figs. $3 \mathrm{~A}$ and $4 \mathrm{~A}$. The high-water level keeps for 10 hours from 25 to 35 hours, during which the phreatic surface does not reach the steady state position (the steady state phreatic surface is shown in figs 3 and 4 in dark red). The water rise rate of $0.7 \mathrm{~m} /$ hour does not enable to establish steady state seepage in the prism of the dam with the core (fig. 3A), so the water saturation of the soil in the core is less than in the screen soil, which is located closer to the upstream slope. The screen is saturated with water more intensely even at the first 20 hours of the flood.

After the short period of high water, the water level begins to decrease, the falling rate reaches of $0.78 \mathrm{~m} /$ hour at the time period from 35 hours to 55 hours (figs. $3 \mathrm{~B}$ and $4 \mathrm{~B})$. The direction of water movement changes: part of the water continues to seep through the downstream slope, as evidenced by the gradual increase in water level inside downstream prism and approaching the steady state position, the second part changes direction to the upstream slope. The figs. $3 \mathrm{~B}$ and $4 \mathrm{~B}$ show that the reduction of pore pressure in the dam prism occurs almost simultaneously with the water level decrease in the MFC Reservoir, and the lag time of the phreatic surface is
- the mechanical soil properties in saturated and

formed due to the low hydraulic conductivity of the core and screen. The location of the impermeable layer (screen) near the upstream slope significantly affects the pressure gradient during the water level falling.

Therefore, from the point of view of reliable operation of the MFC Reservoir, the impermeable layer should be moved away from the upstream slope to decrease the pressure gradient and fast the pore pressure damping in the dam prism.

The fig. 5 presents the results of upstream slope stability calculations by the SAM for the dam models with core and screen and the change of water levels in the MFC Reservoir, which corresponds to the transformed flood hydrograph. The zero time corresponds to the upstream slope stability at the steady state water level of $1.0 \mathrm{~m}$ above the dam base. The Safety Factor of the upstream slope of the dam is 1.5 at the zero time, which is lower than the SF of the MFC Reservoir filled with water due to the stabilizing effect of hydrostatic pressure. At the begin of the flood (from 0 to 10 hours) during the slow water raising, the SF of the upstream slope decreases slightly due to increasing pore pressure in the dam prism, the next time period with increasing water level the stability of the slope increases to 1.57 for the dam with core and to 1.5 for the dam with screen.

After 35 hours of the flood, the water level begins to fall, the water level in the MFC Reservoir falls faster than the phreatic surface in the dam body and the slope stability decreases, reaching a minimum value at the 50th hour of flood, which corresponds to the highest gradient of phreatic surface (figs. 3B, 4B). The upstream slope of the dam with the screen loses stability faster than the dam with the core and Safety Factor reaches the limit value at which the slope is kept stable at 50th hour. At the same time, the dam with the core has the safety margin.

Dam stability simulation by the SRM demonstrates the similar trend of Safety Factor change with the maximum value at the highest water level in the MFC Reservoir during the flood and the minimum value of the upstream slope stability at the 50th hour (the end of the flood). At the end of the flood, the upstream slope is stabilized with the gradual restoration of the initial Safety Factor. The results of calculations are shown in the fig. 6 .

Calculated sliding surfaces by SRM and SAM had circular shapes. The location of the critical sliding surfaces determined by the SRM and SAM were situated on the upstream berm. The sliding surface determent by SRM is located deeper and has bigger radius than surface designed by SAM. The sliding area created by SRM is bigger.

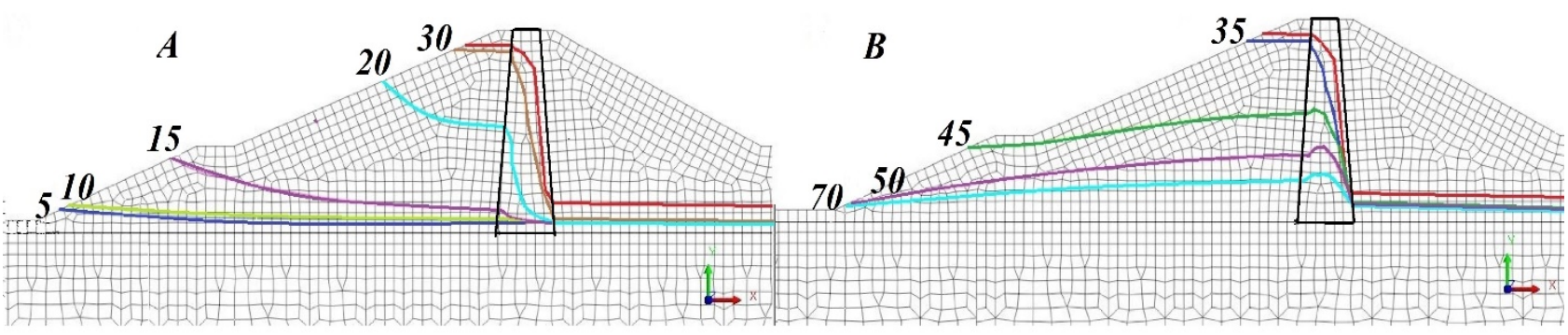

Fig. 3. The phreatic surface location at the $5,10,15,20,30,35,45,55$ and 70 hours of the flood inside the dam with the core. 


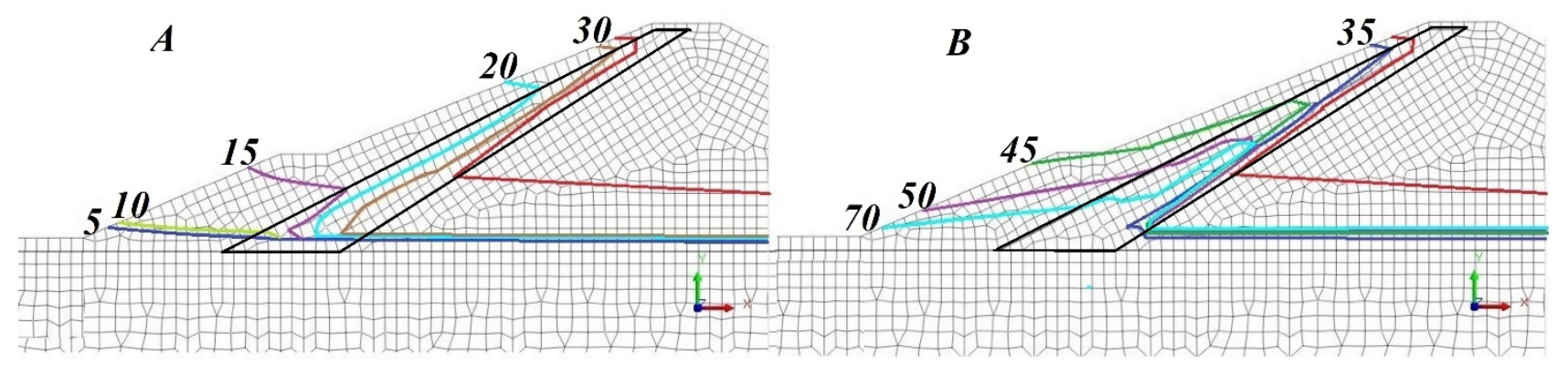

Fig.4. The phreatic surface location at the 5, 10, 15, 20, 30, 35, 45, 55 and 70 hours of the flood inside the dam with the screen.

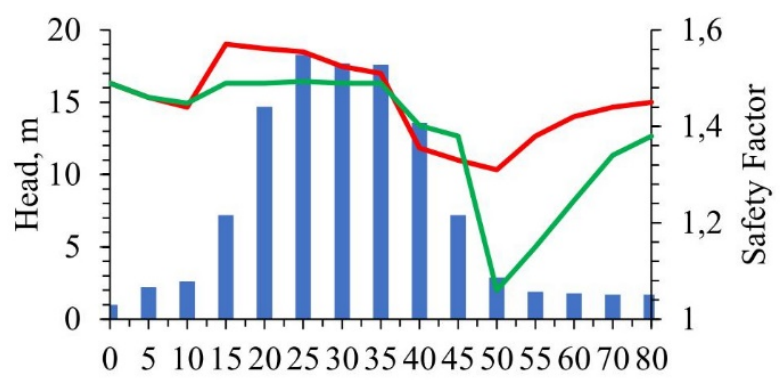

time, hour

Flood $\longrightarrow$ Dam with core $\longrightarrow$ Dam with screen

Fig. 5. The Safety Factor of the upstream slope of the dam with core and screen calculated by the SAM.

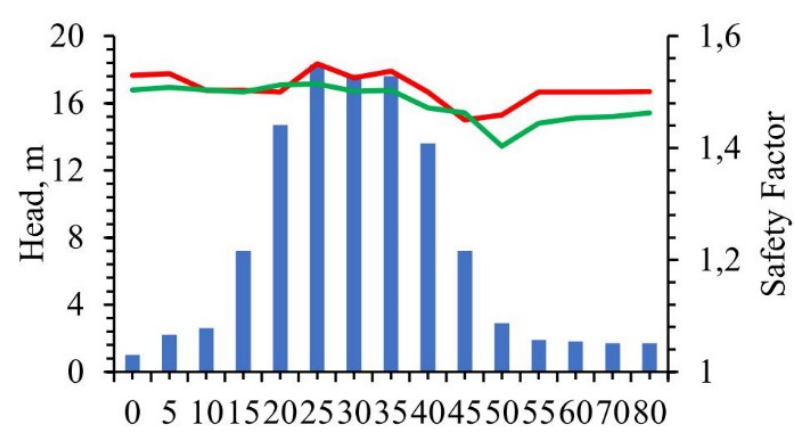

time, hour

Flood —Dam with core —Dam with screen

Fig. 6. The Safety Factor of the upstream slope of the dam with core and screen calculated by SRM.

\section{Conclusions}

Floods in mountainous areas have a sudden nature and the short period of 2-3 days, with a significant water rise in short time and the same rapid water level falling. Construction of the Mountain Flood Control Reservoir requires rockfill dam. Two different type of the impermeable layer of the dam were used for simulation: the dam with core and the dam with screen.

When the water level rises to the maximum value and then falls, there is the water lag time in the impermeable layer, especially great seepage gradient takes place in the dam with the screen.

The dam prism with the hydraulic conductivity of 20 $\mathrm{m}$ /day leads to pore pressure damping, so in a dam with the core phreatic surface are gentler, and the seepage point almost coincides with the water level in the MFC Reservoir. In the dam with screen, the water lag in the screen soil leads to the larger values of pore pressure near the upstream slope, and the seepage point is situated above the water level in the MFC Reservoir.

The Safety Factor of the upstream slope of the dam is 1.5 for initial position, when the MFC Reservoir is empty and the initial river water level is $1.0 \mathrm{~m}$ above the base.

Seepage analysis of the rockfill dam with impermeable layer showed that the maximum values of the Safety Factor is achieved by setting the high-water level in the MFC Reservoir. The flood condition does not enable to form of steady state seepage due to the low hydraulic conductivity $(0.067 \mathrm{~m} /$ day $)$ of the impermeable layer and the high-water level changing rate in the MFC Reservoir. Therefore, simulation of the MFC Reservoir operation must be carried out using transient seepage analysis, taking into account the unsaturated properties of the soil.

Simulations of the dam with core under transient condition of water level rising and falling showed that the upstream slope stability significantly depends on the position of the phreatic surface in dam prism. On the example of the dam with core on the Irshava River, the simulation using SAM showed that the water level falling at the end of the flood reduces the slope stability, the Safety Factor was 1.31 when the minimum water level is reached.

The water level falling under transient condition in the unsaturated soils by SRM also leads to the decrease of the upstream slope stability, but the minimum value of the Safety Factor was 1.48 for the dam with core.

The dam with screen as impermeable layer has operational advantages, but in the case of transient seepage condition, the screen saturation leads to the significant increase in the phreatic surface gradient that reduce the slope stability to unacceptable Safety Factor values of 1.06 . Therefore, the rockfill dam with the clay core significantly increases the reliability and safety of the structure and ensures the upstream slope stability. The dam prisms should have high hydraulic conductivity and the slopes should be divided with berms of $3.0 \mathrm{~m}$ width.

Calculations of slope stability by SAM and SRM show the circular sliding surface and not the same location of the critical sliding surface. The values of the Safety Factor under the same conditions differ due to the different radius of the sliding surface and location. The values of the Safety Factor calculated using the SAM are lower than the value determined by SRM under similar conditions. 
The overestimated Safety Factor by SRM were obtained in the works [20 - 24], that explained sensitive to the nonlinear solution algorithm and its incapable of determining other failure surfaces near critical value.

Since the Safety Factor values defined by SAM lower, they were taken to assess the upstream slope stability.

\section{References}

1. O. Obodovskiy, Y. Obodovskiy V. Onischuk, Geography and tourism. 4(2), 89-99 (2016). doi: 10.5281 /zenodo. 223943

2. S. Velychko, O. Dupliak, Problemy vodopostachannia, vodovidvedennia ta hidravliky. 20, 45-52 (2014).

3. D. Zumr, M. Císlerová. J. Hydrol. Hydromech., 58, 1, 64-72 (2010). doi: 10.2478/v10098-010-0007-z

4. G. Gottardi, C. Gragnano, E3S Web of Conf. 919002 (2016). doi:10.1051/e3sconf/20160919002

5. A. Zewdu, World News of Natural Sciences. 26, 191217 (2019)

6. M. Fattah, Y. Omran, M. Hassan, Acta Montanistica Slovaca. 22(1), 43-57 (2017).

7. T. Alfatlawi et al., in IOP Conf. Ser.: Mater. Sci. Eng. 671012072 (2020). doi: 10.1088/1757899X/671/1/012072.

8. S. Athania, Shivamantha, C. Solankia, G. Dodagoudarb, Aquatic Procedia 4, 876 - 883 (2015.). doi: 10.1016/j.aqpro.2015.02.110

9. A. Bhutto, G. Bhurgri, S. Zardari, M. Zardari, R. Bhanbhro, B. Memon, Engineering, Technology \& Applied Science Research. 10 (2), 5496-5500 (2020). doi: 10.48084/etasr.3211

10. Q. Liu, J. Li, Procedia IUTAM 17, 29 - 39 (2015). doi: $10.1016 /$ j.piutam.2015.06.006

11. R. Usama, Sh. Khayyun, Eng. and Tech. J., 36, A, 5, 523-532 (2018). doi:10.30684/etj.36.5A.8.

12. P. Talukdar, A. Dey, In: Prashant A., Sachan A., Desai C. (eds) Advances in Computer Methods and Geomechanics. Lecture Notes in Civil Engineering, 56 (2020). Springer, Singapore. doi: 10.1007/978981-15-0890-5_45

13. J. Mao, J. Guo, Y. Fu, W. Zhang, Y. Ding, Advan. in Civ. Engin. 2020, ID 2360947 (2019). doi:10.1155/2020/2360947

14. G. Pauls, E. Sauer, E. Christiansen, R. Widger, Canadian Geotech. J., 1999, 36(6) 1151-1171 (2011). doi: 10.1139/t99-073.

15. A. Carastoian, Energy Procedia, 85, January, 93-98 (2016). doi: 10.1016/j.egypro.2015.12.278.

16. S. Nam, M. Gutierrez, P. Diplas, J. Petrie, GeoCongress Technical Papers: Geo-Characterization and Modeling for Sustainability. Geo-Congress 2014 Technical Papers, GSP 234 (C) ASCE, 4097-4104 (2014). doi: 10.1061/9780784413272.398

17. F. Huang, X. Luo, W. Liu, Water. 9(7), 450 (2017). doi:10.3390/w9070450.
18. S. Seyed-Kolbadi, J. Sadoghi-Yazdi, M. HaririArdebili, Geosciences 2019, 9(1), 55 (2019). doi:10.3390/geosciences9010055.

19. Z. Niu, R. You, J. Lu, Procedia Engineering 28, 560563 (2012). doi: 10.1016/j.proeng.2012.01.768

20. H. Moon, J. Shim, J. Jeong, S. Lee, J. of Engin. Geology, 27(1), 31-40 (2017). doi:10.9720/kseg.2017.1.31.

21. Y. Cheng, T. Lansivaarab, W. Wei. Computers and Geotechnics, 34(3), 137-150 (2007). doi:10.1016/j.compgeo.2006.10.011.

22. C. Zhou, W. Shao, C. van Westen. Engin. Geology, 173, 41-51 (2014). doi: 10.1016/j.enggeo.2014.02.004

23. R. Zhang, J. Zhao, G Wang. Mathematical Problems in Engineering. 2016, ID 7857490 (2016). doi: $10.1155 / 2016 / 7857490$

24. S. Liu, L. Shao, H. Li, Computers and Geotechnics. 63, 291-298 (2015).

doi:10.1016/j.compgeo.2014.10.008 